\title{
CASEREPORT
}

\section{Management of Gingival Pigmentation with Diode Laser: Is It a Predictive Tool?}

Yogesh Doshi, Nikhil Khandge, Girish Byakod, Priya Patil

\begin{abstract}
Today, an attractive smile is the vogue for many individuals. Gingival health and appearance are essential components for an attractive smile and removal of unsightly pigmented gingival is the need for a pleasant and confident smile. In some populations, gingival pigmentation seems to be a genetic trait and is irrespective of age and gender, hence gingival pigmentation is termed as physiologic or racial gingival pigmentation. Intraoral pigmentation is seen due to the presence of the fundamental pigment melanin that colors the tissues. Several treatment modalities have been suggested for gingival depigmentation. Many varying results have been observed, but the repigmentation has been documented to occur. The large variation in time of repigmentation may be related to the techniques used and the race of the patient. This case report demonstrates the probable cause of repigmentation where pigmentation has recurred limbs.
\end{abstract}

Keywords: Melanin, Laser, Keratinocytes, Melanocytes.

How to cite this article: Doshi Y, Khandge N, Byakod G, Patil P. Management of Gingival Pigmentation with Diode Laser: Is It a Predictive Tool?. Int J Laser Dent 2012;2(1):29-32.

\section{Source of support: Nil}

Conflict of interest: None

\section{INTRODUCTION}

Any feeling of pleasure, happiness, laughter or simply a greeting leads to a smile resulting in the exposure of teeth and gingival. If this exposure is optimal, then the result is a beautiful smile. A smile is not only a method of communication but is also a medium of socialization, interaction and attraction. The harmony of the smile is not only determined by the shape, position and the color of the teeth but also by the level and color of the gingival tissues. One of the major factors involved in the evaluation of smile is the color of the gingival which is typically coral pink. The factors that affect the gingival color include its vascularity, thickness, keratinization and gingival pigmentation. ${ }^{1}$ Gingival pigmentation may appear as early as 3 hours after birth. ${ }^{2}$ Oral melanin pigmentation is well documented in the literature and is considered to be multifactorial. Whether the condition is physiological or pathological, it can be caused by a variety of local and/or systemic factors ${ }^{3,4}$ including genetic, tobacco use, ${ }^{5-7}$ prolonged administration of certain drugs especially antimalarial agents and tricyclic antidepressants. ${ }^{8}$ Gingival pigmentation has been classified as: ${ }^{9} 0$ —no pigmentation; 1 -solitary unit(s) of pigmentation in papillary gingiva without extension between neighboring solitary units; 2 formation of continuous ribbon extending from neighboring solitary units (Fig. 1).
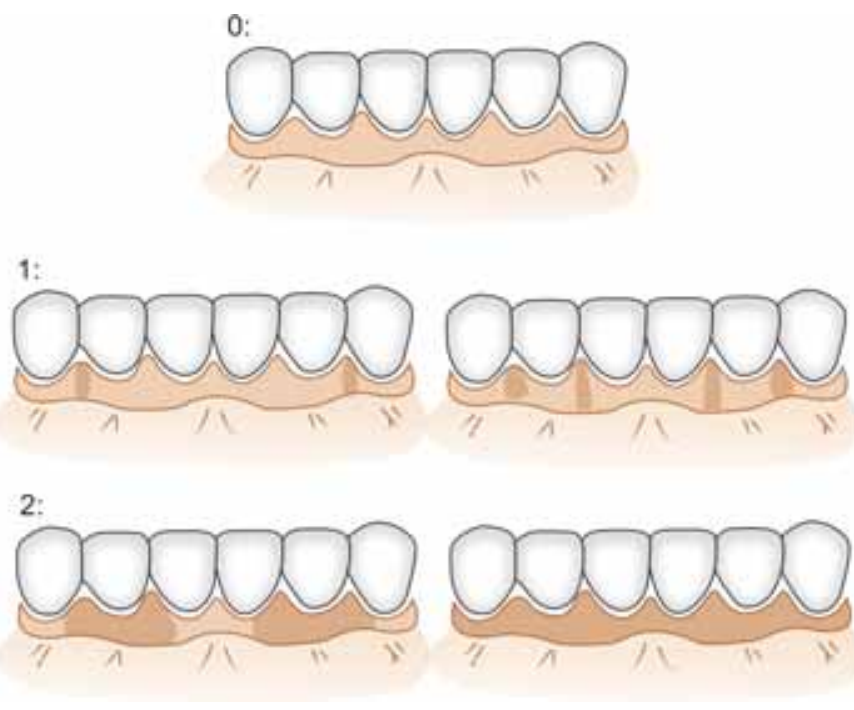

Fig. 1: Gingival pigmentation classification

Various procedures have been proposed for removal of the gingival pigmentation and to restore esthetics. These techniques include gingivectomy, ${ }^{10}$ free gingival autografts, surgical depigmentation, ${ }^{11}$ electrosurgery, ${ }^{12}$ cryotherapy, ${ }^{13,14}$ use of rotary instruments, chemical agents like phenol and alcohol ${ }^{15}$ and lasers. ${ }^{16}$

Lasers were first introduced in 1960 by Maimanand and were brought into general practice by Dr William and Terry Myers. ${ }^{17}$ Although, $\mathrm{CO}_{2}$ lasers are very commonly used for depigmentation procedure, they can damage tooth structure and the delivery system is very cumbersome. Since $\mathrm{CO}_{2}$ lasers are used in noncontact mode, they can also cause loss of tactile sense. ${ }^{17}$ Also, diode is an excellent soft tissue laser and is indicated for cutting and coagulating gingival tissue. ${ }^{18,19}$ Thus, we decided to use diode lasers. Wavelengths of diode laser are highly absorbed by pigmented tissue. This case report presents recurrence of gingival repigmentation after depigmentation was carried out using a diode $(940 \mathrm{~nm})$ laser, but the pigmentation was comparatively mild.

\section{CASE REPORT}

An 18-year-old Indian female reported to dental office with a chief complain of gingival pigmentation. On examination, gingiva was found to be periodontaly healthy with class 2 
gingival pigmentation (Fig. 2). The patient was a nonsmoker and the pigmentation appeared to be of ethnic origin. She was informed of the various techniques that were available for gingival depigmentation. After an informed consent, it was decided to use a diode laser $(940 \mathrm{~nm}$ ) (Ezlase, Biolase Irvine, California, USA) to carry out the gingival depigmentation procedure. Local anesthesia (Lignox 2\% Warren Pharma Maharashtra, India) was administered. A 400 micron tip was initiated using an initiator cork. The gingival epithelium and part of connective tissue was removed using $2.5 \mathrm{~W}$ pulsed mode. Pulse length and pulse interval were used for 0.50 microseconds. The tip was moved using brush strokes to prevent heating of the tissue. The area was irrigated using saline and was covered with periodontal dressing for 1 week (CoE Pak GC, Asia Hyderabad). Patient was recalled at the intervals of 1 week, 6 month and 1 year. Postoperatively, the gingival appeared pink color at the end of 1 week (Fig. 3 ) but when the patient returned after 6 months for follow-up, mild patchy pigmentation had reappeared (Fig. 4). The pigmented area further increased in size after 1 year (Fig. 5). The intensity of pigmentation was less compared to pretreatment intensity.

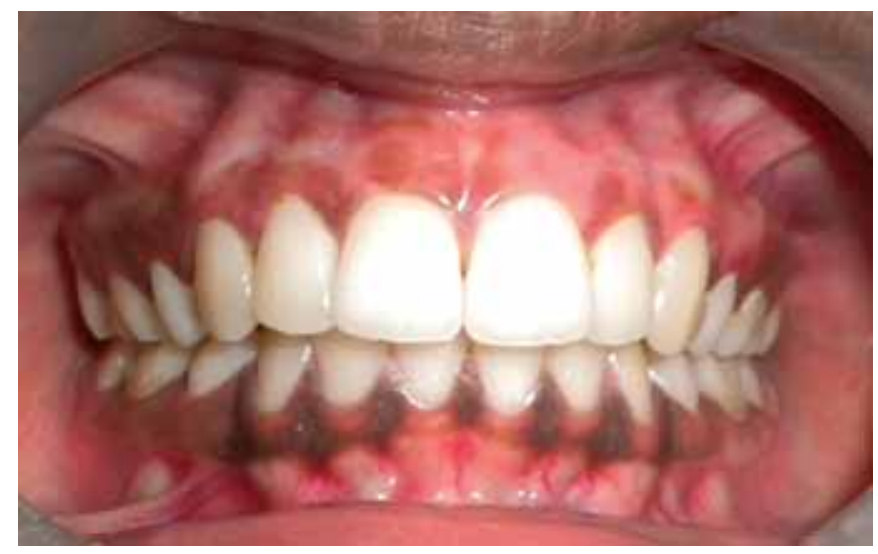

Fig. 2: Pretreatment photograph

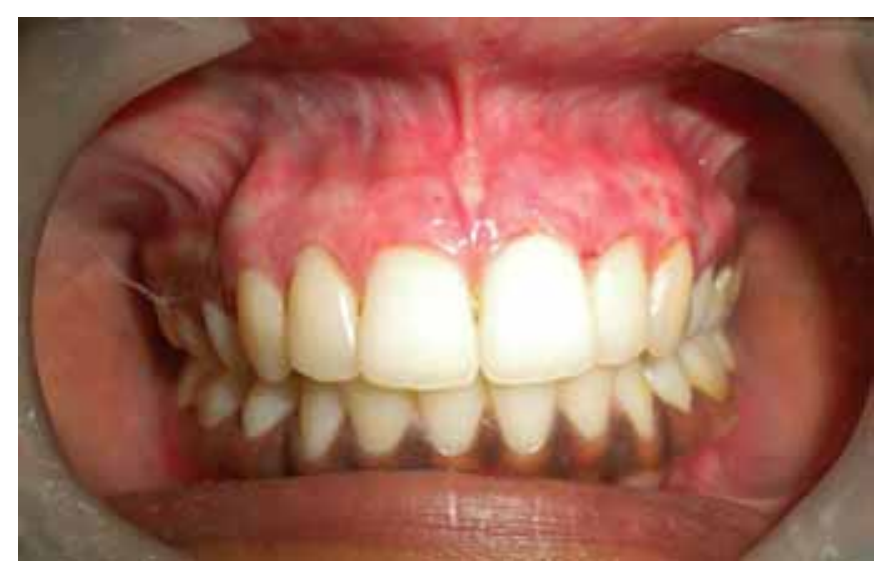

Fig. 3: Seven days postoperative photograph

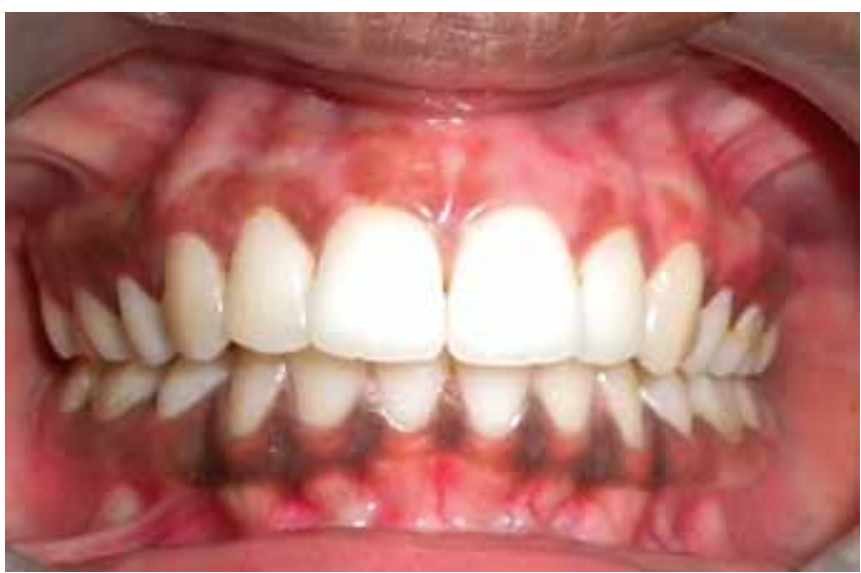

Fig. 4: Six months postoperative photograph

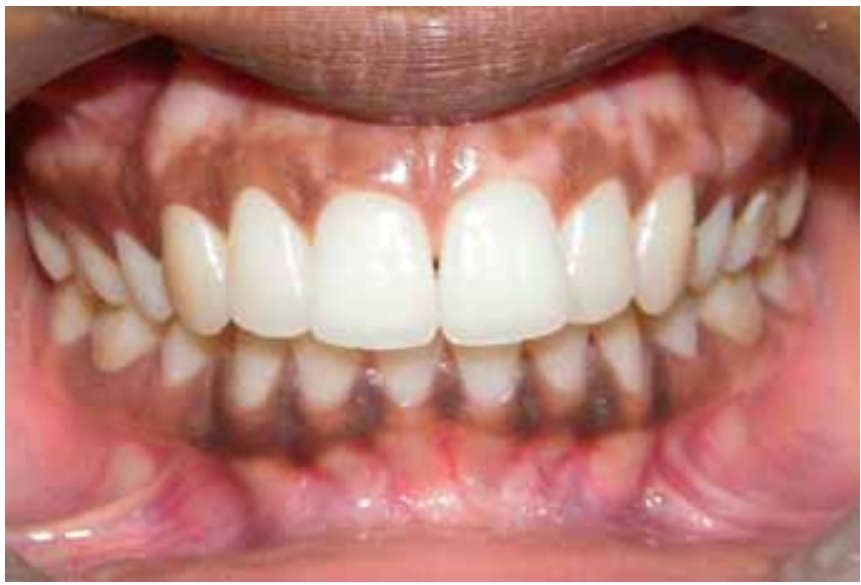

Fig. 5: One year postoperative photograph

\section{DISCUSSION}

Gingival pigmentation often forces the patient to seek therapy. Although various methods have been suggested for depigmentation, lasers are preferred for a number of advantages. Diode laser causes minimal damage to the periosteum and bone and it has the unique property of cleanly removing a thin layer of epithelium. Although healing of laser wounds is slower than healing of scalpel wounds, a sterile inflammatory reaction occurs after lasing. ${ }^{20}$

Also the advantages of laser include: ${ }^{21-24}$

1. A relatively bloodless surgical field

2. The ability to coagulate, vaporize or cut tissues

3. Sterilization of the wound site

4. Minimal swelling and scarring

5. Little mechanical trauma

6. High patient acceptance

7. Less postoperative pain, which may be due to the protein coagulum that is formed on the wound surface, sealing the ends of the sensory nerves

8. Smaller size of the units as well as the lower financial costs. 
Initiation of the tip provides a hot tip effect which helps in concentrating energy at the tip. ${ }^{17}$ This helps in the easy removal of superficial cell layer and partly connective tissue without profuse bleeding or trauma to the mucosa. Melanin is produced by specialized pigment cells in gingiva called melanocytes. They are located in the basal layer of epithelium and epidermis. Hence, it is necessary to remove a part of the epidermis. The wound healing takes place by proliferation of cells present along the periphery of the wound. These cells migrate and help in reepithelialization of the wound. ${ }^{25}$ Oral repigmentation refers to clinical reappearance of melanin pigment after a period of clinical depigmentation of the oral mucosa. ${ }^{1}$ In this case, the pigmentation started to reappear after 3 months and during the 6 months follow-up period, the patchy pigmentation started to appear. The patchy pigmentation could be a result of the ongoing process of repigmentation. The decreased intensity of pigmentation may be due to less production of pigments. The intensity may increase with time and may reach to pretreatment level as it depends on the racial background of the patient. Similarly, Kon et al study was consistent with our findings; who demonstrated that permanent results can not be offered when gingival depigmentation procedures are performed for cosmetic reasons. ${ }^{26}$ Also, Perlmutter and Tal reported the case of one patient in whom gingival repigmentation occurred 7 years after removal of gingival tissues. ${ }^{27}$ Dummet and Bolden observed partial recurrence of hyperpigmentation in six out of eight patients after gingivectomy at 1 to 4 months. ${ }^{28}$ Nakamura et al described depigmentation with $\mathrm{CO}_{2}$ laser in 10 patients. No repigmentation was seen in 1st year but four patients showed repigmentation by 24 months. ${ }^{29}$ The recurrence of pigmentation can be due to the nature of melanocytes. These cells arise from neural crest ectoderm and enter epithelium as melanocytes from about 8th gestational week and by 14th week, these cells may have reached densities of $2000 / \mathrm{mm}^{2}$ in some regions. Melanocytes have a reproductive self-maintaining system of cells. ${ }^{30}$ When locally depleted, they repopulate and keratinocytes derived growth factors FGF- $\beta$ involve as mitogen. ${ }^{31}$ These cells lack desmosomes and possess long dendritic processes that extend between keratinocytes. Melanin is synthesized in melanocytes in small structures called melanosomes. These melanosomes are injected into the keratinocytes by the dendritic processes. All individuals, whether lightly or darkly pigmented have same number of melanocytes in any given region of mucosa. But, it has been observed that cells with melanin are present in connective tissue in the case of individuals who have a very high melanin pigment. These cells are actually macrophages that engulfed the melanin pigment. ${ }^{32}$

\section{CONCLUSION}

Thus, the above case demonstrates that although lasers provide a lot of advantages for such cases, they are not the ultimate tool in the management of gingival pigmentation. Great caution must be exercised while selecting cases for depigmentation. Recurrence of pigmentation is dependent on racial background, habits and techniques. The expectations of the patient must be analyzed properly and the patient should be well informed before the procedure about recurrence. Hence, it is clear that people who are racially prone for gingival pigmentation need to be careful while undergoing such treatment since the results do not sustain for long time. Since, very little data is available on repigmentation after therapeutic procedures; long-term follow-up of such patients should be carried out to determine the time frame of repigmentation.

\section{REFERENCES}

1. Fiorelline JP, Kim DM, Uzel NG. Anatomy of the periodontium. newmann, Takei, Klokkevold, Carranza: Carranza’s clinical periodontology (11th ed). Elsevier 2011;12-27.

2. Dummett CO. Physiologic pigmentation of the oral and cutaneous tissue in the Negro. J Dent Res 1946;25:421.

3. Dummett CO, Barens G. Oromucosal pigmentation: An updated review. J Periodontol 1971;42:726-36.

4. Steigmann S. The relation between physiologic pigmentation of the skin and the oral mucosa in Yemenite Jews. Oral Surg 1965;19:32-38.

5. Hedin CA. Smoker's melanosis. Occurrence and localization in the attached gingiva. Arch Dermatol 1977;113:1533-38.

6. Axell T, Hedin CA. Epidemiologic study of excessive oral melanin pigmentation with special reference to the influence of tobacco habits. Scand J Dent Res 1982;90:434-42.

7. Araki S, Murata K, Ushio K, Sakai R. Dose-response relationship between tobacco consumption and melanin pigmentation in the attached gingiva. Arch Environ Health 1983;138:375-78.

8. Kanakamedala AK, Geetha A, Ramakrishnan T, Emadi P. Management of gingival hyperpigmentation by the surgical scalpel technique: Report of three cases. J Clinical and Diagnostic Research April 2010;4(2):2341-46.

9. Hanioka T, Tanaka K, Ojima M, Yuuki K. Association of melanin pigmentation in the gingiva of children with parents who smoke. Pediatrics Aug 2005;116(2):186-90.

10. Tamizi M, Taheri M. Treatment of severe physiologic gingival pigmentation with free gingival autograft. Quintessence Int 1996; 27(8):555-58.

11. Almas K, Sadig W. Surgical treatment of melanin pigmented gingiva: An esthetic approach. Indian J Dent Res 2002;13(2): 70-73.

12. Gnanasekhar JD, Al-Duwairi YS. Electrosurgery in dentistry. Quintessence Int 1998;29(10):649-54.

13. Tal H, Landsberg J, Kozlovsky A. Cryosurgical depigmentation of the gingiva: A case report. J Clin Periodontol 1987; 14(10):614-17.

14. Yeh CJ. Cryosurgical treatment of melanin-pigmented gingiva. Oral Surg Oral Med Oral Pathol Oral Radiol Endod 1998; 86(6):660-63. 
15. Hasegawa A, Okagi H. Removing melagenous pigmentation using 90 percent phenol with 95 percent alcohol. Dent Outlook 1973;42:673-76.

16. Lagdive S, Doshi Y, Marawar PP. Management of gingival hyperpigmentation using surgical blade and diode laser therapy: A comparative study. J Oral Laser Application Spring 2009;9(1): 41-48.

17. Coluzzi D. Fundamentals of dental lasers: Science and instrument. Dent Clin N Am 2004;751-70.

18. Moritz A, Gutknecht N, Doerbudak O. Bacterial reduction in periodontal pockets through irradiation with diode laser. J Clin Laser Med Surg 1997;15:33-37.

19. Coluzzi D. Lasers and soft tissue curettage: An update. Compendium 2002;23:1104-11.

20. Semih Ozbayrak, et al. Treatment of melanin pigmented gingiva and oral mucosa with $\mathrm{CO}_{2}$ laser. Oral Surg Oral Med Oral Pathol Oral Radiol Endo 2000;90:14-15.

21. Pick PH, Pecaro BC, Silberman CJ. The use of $\mathrm{CO}_{2}$ laser for the removal of phenytoin hyperplasia. J. Periodnontol 1985;56: 492-94.

22. Rossman JA, Gottlieb S, Koudelka BM, McQuade MJ. Effect of $\mathrm{CO}_{2}$ laser irradiation gingiva. J Periodontol 1987;58:423-25.

23. Moritz A, Schoop U. Treatment of periodontal pockets with a diode laser. Lasers Surg Med 1998;22:302-11.

24. Zhang XY, Al-Watban FA. Comparison of the effects of laser therapy on wound healing using different laser wavelengths. Laser Ther 1986;8:127.

25. Mohan H. Inflammation and healing; textbook of pathology (4th ed). Jaypee Publication 2000;114-60.

26. Kon S, Bergamaschi O, Dome Al, Ruben MP. Melanin repigmentation after gingivectomy: A 5-year clinical and transmission electron microscopic study in humans. Int J Periodont Rest Dent 1993;13:85-92.

27. Perlmutter $\mathrm{S}$, Tal $\mathrm{H}$. Repigmentation of the gingiva following surgical injury. J Periodontol 1986;57(1):48-50.

28. Dummett CO, Bolden TE. Postsurgical clinical repigmentation of the gingiva. Oral Surg, Oral Med, Oral Pathol 1963;16:353-57.
29. Nakamura Y, Hossain M, Hirayama K, Matsumoto K. A clinical study on the removal of gingival melanin pigmentation with the $\mathrm{CO}_{2}$ laser. Laser Surg Med 1999;25:140-47.

30. Bannister LH. Ferguson MW, Dussek JE, Dyson M, Collins P, Berry MM, Bannister LH. Integumental system. Gray's anatomy: The anatomical basis of medicine and surgery (38th ed). Churchill Livingstone 1996;375-424.

31. Halaban R, Langdon R, Birchall N, Cuono C, Baird A, Scott G, Moellmann G, McGuire J. Basic fibroblast growth factor from human keratinocytes is a natural mitogen for melanocytes. J Cell Biol Oct 1988;107(4):1611-19.

32. Squier CA, Finkelstein MW. Oral Mucosa. Ten Cate AR: Oral histology development, structure and function (5th ed). Mosby. 1998;345-85.

\section{ABOUT THE AUTHORS}

\section{Yogesh Doshi (Corresponding Author)}

Diploma in Laser Dentistry (SOLA), Senior Lecturer, Department of Periodontics, PDU Dental College, 949, North Sadar Bazar, Saat Rasta Solapur, Maharashtra-413003, India, Phone: 9975626700, e-mail: yogeshdoshi47@gmail.com

\section{Nikhil Khandge}

Diploma in Laser Dentistry (SOLA), IALD, AALZ, Private Practice Mumbai, Maharashtra, India

\section{Girish Byakod}

Professor, Department of Periodontics, MA Rangoonwala Dental College, Pune, Maharashtra, India

\section{Priya Patil}

Lecturer, PDU Dental College, Solapur, Maharashtra, India 